\title{
A propósito de um irmão alemão: a ficcionalização de um assunto internacional de família
}

Georg Wink ${ }^{1}$

Desde o lançamento do livro O irmão alemão, é de conhecimento geral
que Chico Buarque, um dos artistas contemporâneos mais destacados
no Brasil, teve um irmão alemão, já falecido e com quem jamais teve
contato. A notícia surpreendente foi usada como gancho pela editora
Companhia das Letras e amplamente divulgada. Mas quem foi esse
misterioso irmão alemão que menciona o título do livro? Segundo as
informações biográficas, levantadas pelo autor Chico Buarque durante
suas investigações e que constam no último parágrafo do livro
(Buarque, 2014, p. 227), complementadas por pesquisa própria, os fatos são os seguintes: $\mathrm{O}$ irmão alemão físico nasceu em 21 de dezembro de 1930 em Berlim, filho de Anne Ernst e Sérgio Buarque de Holanda, o pai de Chico Buarque, que trabalhara, entre 1929 e 1930, como jornalista em Berlim. Foi registrado como Sergio Ernst, apenas pela mãe, já que o pai tinha voltado ao Brasil antes do parto. Em 1931 ou 1932, foi entregue pela mãe à Secretaria da Infância e da Juventude do distrito de Tiergarten, Berlim. Alguns anos depois, provavelmente em 1935, foi adotado pelo casal Arthur e Pauline Günther e criado com o nome de Horst Günther. Por volta dos 22 anos, ou seja, em 1952, veio a saber da identidade de seus pais naturais e mudou seu nome para Sergio Günther. Entre outras atividades artísticas, trabalhou na televisão do Estado da República Democrática Alemã, vulgo Alemanha Oriental, e tornou-se um cantor bastante famoso, com um número incerto de discos gravados, hoje fora de estoque e raridades nas feiras especializadas em música popular da República Democrática Alemã (RDA). Morreu em 12 de setembro de 1981, um ano antes do pai Sérgio Buarque de Holanda, com quem, pelo que é conhecido, nunca chegou a ter algum contato.

$\mathrm{Na}$ verdade, a mera existência do irmão alemão já era do conhecimento do público interessado antes. Ela é mencionada no ensaio histórico-genealógico, escrito por Bartolomeu Buarque de Holanda, Buarque - Uma família brasileira (2007) e consta também na biografia

\footnotetext{
${ }^{1}$ Doutor em estudos aplicados de língua e cultura espanholas e portuguesas e professor associado de estudos brasileiros da Universidade de Copenhague, Copenhague, Dinamarca. E-mail: georg.wink@hum.ku.dk
} 
escrita por Regina Zappa, Para seguir minha jornada: Chico Buarque (2011). Contudo, não se tinha noção da fantástica carreira artística que este irmão teve, dado que se sabia apenas da existência do filho com o primeiro nome registrado (Sergio Ernst), mas sua identidade como o cantor Sergio Günther era desconhecida. O próprio Chico Buarque declarou, em várias ocasiões, que sabia da existência de seu irmão desde 1967, tendo sido informado por Manuel Bandeira, amigo íntimo do pai. Também disse repetidas vezes que sempre pensou em transformar o assunto internacional de família num livro. Após a morte de sua mãe, em 2010, e supostamente com base em correspondência achada no arquivo familiar, Chico Buarque começou a investir mais seriamente na investigação. Por uma série de coincidências, ganhou a ajuda do historiador João Klug, na época pesquisador visitante no Instituto de Estudos Latino-americanos em Berlim, o que felizmente resultou no esclarecimento dos fatos acima descritos (Neher, 2014). Finalmente, em 2013, Chico viaja a Berlim para encontrar a ex-mulher de Sergio Günther, Monika Knebel, a filha Kerstin Prügel e a neta Josepha Prügel, além de entrevistar alguns amigos. Uma segunda visita, em novembro de 2014, foi coberta por uma reportagem do diário português Público, com a matéria publicada em 25 de janeiro de 2015 (Silva, 2015). As fotos mostram o encontro, diante do antigo apartamento de Sergio Günther, que é um lugar bastante significativo: fica num endereço que, na época da RDA, chamava-se Praça Lênin (hoje Praça das Nações Unidas) e faz parte de um complexo habitacional de cerca de 1.200 apartamentos, hoje tombado, desenhado para ser uma vitrine do urbanismo socialista. Os domicílios eram reservados a altos funcionários do Partido Socialista Unificado ou a celebridades. No meio da praça, havia uma estátua do revolucionário, que foi demolida logo depois da queda do muro (o reboque da estátua virou a famosa cena-chave do longa-metragem alemão Adeus Lênin, de 2003, dirigido por Wolfgang Becker).

Sergio Günther, celebridade possuidora do direito à moradia VIP, não passou pela experiência de ver o próprio país naufragando, já que faleceu em 1981. Talvez tenha sido melhor assim, porque ele era assumidamente um "artista do regime": como apresentador de TV e rádio, como humorista (sempre leal à linha oficial), como cantor que gravou a canção "Aos apolíticos", com a letra altamente conformista de Helmuth Preissler, em lugar do poema homônimo e incômodo de Bertolt Brecht (Trzoss, 
2009, p. 98). ${ }^{2}$ Para os repórteres do Público, Chico Buarque brinca com a conclusão de que o irmão dele deveria ter sido "uma espécie de Faustão da Alemanha Oriental" (Silva, 2015). Guardadas as devidas proporções, talvez tenha sido até uma espécie de Roberto Carlos, sutilmente compromissado com o regime (Mota, 2005). Essa comparação, obviamente, teria implicações muito severas e talvez por isso não tenha ocorrido a Chico Buarque. Mas não deixa de ser curioso que Chico Buarque, socialista declarado, censurado, perseguido e autoexilado em 1969, teve um irmão que fez, exatamente na mesma época, carreira como artista oficial do regime socialista realmente existente na RDA.

Sem entrar em especulações sobre as veredas misteriosas do destino, prefiro abandonar, por enquanto, a contextualização e focar o texto ficcional $O$ irmão alemão, para abordar, primeiramente, a grande questão: por que e como o incidente internacional na história familiar do autor foi transformado em livro? Para tal empreendimento, é preciso começar com um breve resumo da trama, organizada em 17 capítulos.

No primeiro, o narrador em primeira pessoa, Francisco de Hollander, chamado de Ciccio, em 1960 e com 16 anos de idade, encontra uma carta de 1931 (transcrita no livro), dirigida ao seu pai, Sérgio de Hollander. Nesta, uma ex-namorada em Berlim, Anne Ernst, informa-lhe que o filho Sergio que eles têm em comum vai fazer um ano e que, dado o silêncio do pai biológico, ela vai se sentir livre para unirse a outro, Heinz Bogart. A leitura tem um forte efeito sobre o narrador protagonista. Ciccio começa a pensar obsessivamente no irmão e na distante Alemanha, onde ele supõe que este viva. Numa espécie de atividade compensatória, começa a frequentar lugares "alemães" em São Paulo, tomando Steinhäger na cervejaria Zillertal e na boate Sans Souci. O capítulo inclui, quase como brinde, algumas aventuras de juventude que já foram motivo da boataria sobre o autor Chico Buarque. Prazerosamente, são narradas uma série de contravenções a leis, se factuais ora prescritas, como, infração ao Código Penal no que diz respeito aos artigos 155 (furto qualificado de carro) e 176 (estelionato e outras fraudes, leia-se: calotes), além de transgressões aos artigos 208 (avançar o sinal vermelho), 181 (estacionar na pista de rolamento) e 305 (afastamento do local de acidente) do Código de Trânsito.

2 Estão disponíveis no Youtube duas canções de Sergio Günther, ambas de 1961: Mitternachtstango, ou Tango da meia-noite (https://www.youtube.com/watch?v=KHHbV5C-Gpo) e Geisterfox, ou Fox dos Fantasmas (https://www.youtube.com/watch?v=qvMHtWkMCXE). 
O segundo capítulo é uma retrospectiva sobre a própria infância e uma homenagem ao pai, homme de lettres, numa apresentação algo parecida com aquela do documentário de Nelson Pereira dos Santos, Raízes do Brasil, de 2004.

O terceiro capítulo explora alguns possíveis destinos do irmão alemão, que poderia ter sido morto na $2^{\text {a }}$ Guerra Mundial, poderia ter se convertido ao judaísmo, poderia estar em São Paulo à procura do pai, entre outros.

O quarto se dedica a contar as aventuras eróticas do seu irmão maior brasileiro, Domingos, com o qual, ao contrário do irmão alemão, o narrador convive.

No quinto, temos uma descrição do contexto histórico do golpe militar, com destaque à Marcha da Família com Deus pela Liberdade, em 1964, além de uma cena na qual o narrador pergunta ao pai sobre o misterioso irmão alemão.

Nos capítulos 6 a 10, o narrador acredita ter descoberto a mãe de seu irmão, Anne Ernst, e seu novo marido Heinz Borgart, já mencionado na carta, em São Paulo, sob o sobrenome Beauregard. Com bastante dificuldade, ele arranja uma visita à família e investiga o caso, o que resulta numa série de novas narrativas hipotéticas sobre um passado possível.

No capítulo 11, Ciccio descobre uma carta do Consulado da Alemanha - a qual, além de transcrita, também foi fotografada e incluída no livro, como primeira intrusão comprovada do contexto biográfico. Curiosamente, o documento verídico (figura 1) mostra que, para as autoridades alemãs, a grafia do sobrenome de seu pai era, erroneamente, "Hollander", nome comum na Alemanha, em lugar de "Holanda", nome que seria desconhecido, sendo que o erro se explica, em parte, porque a pronúncia alemã das duas palavras seria igual. Aparentemente, o correspondente estrangeiro Sérgio Buarque de Holanda nunca sentiu a necessidade de corrigir o erro - ou temia as consequências burocráticas. $\mathrm{O}$ mais importante, porém, é o conteúdo. A carta se refere a uma anterior, datada do dia 31 de agosto de 1932, que trata da negociação do pagamento pelo pai de uma pensão alimentícia em benefício do filho alemão ou, como alternativa sugerida por Sérgio, de providenciar a mudança da criança para o Rio às suas custas. $O$ narrador encontra também uma foto de Anne (não reproduzida no livro) - para espanto dele, em nada parecida com Mme Beauregard. 


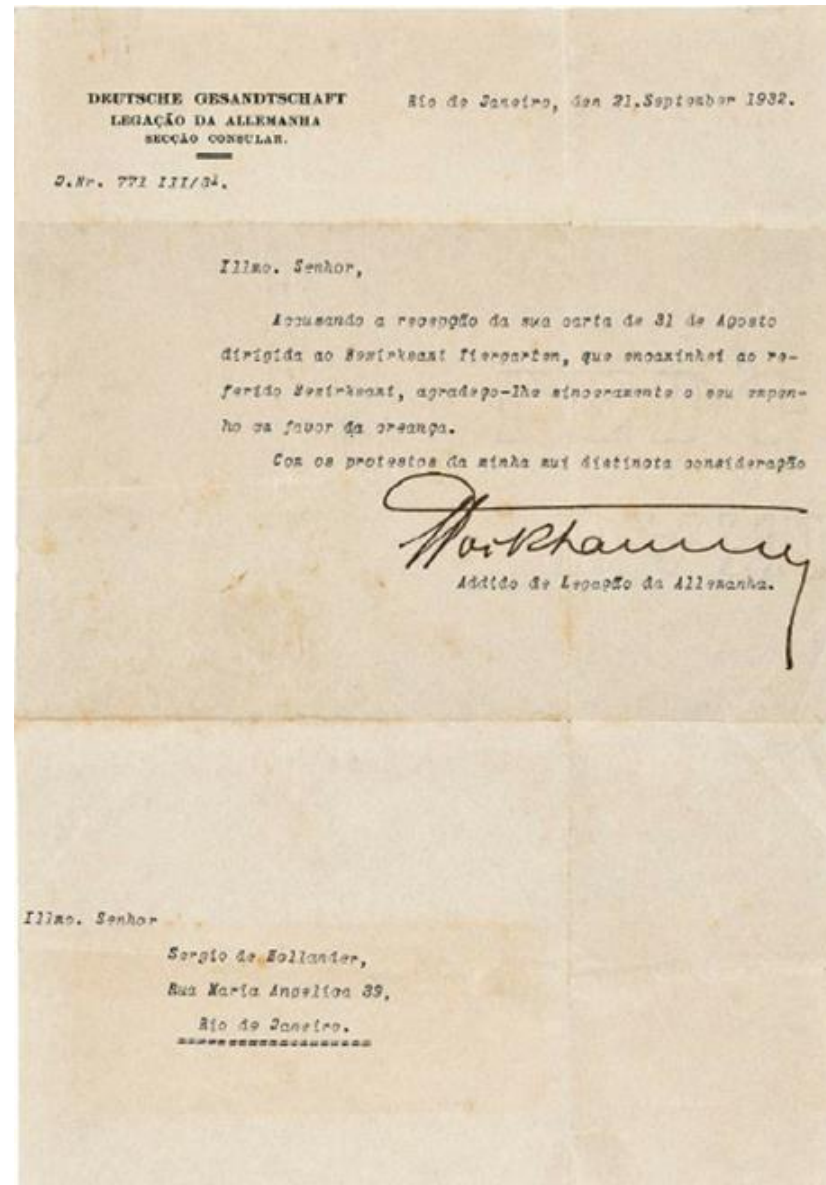

Figura 1 - Carta do Consulado da Alemanha no Rio de Janeiro do dia 21 de setembro de 1932 (Buarque, 2014, p. 114).

Nos capítulos 12 e 13, o narrador trava contato com o filho do casal, Christian, embora sabendo que ele não poderia ser o seu desejado irmão. Surge, durante as conversas com o aficionado em literatura, a ideia de escrever um livro sobre o irmão alemão. Enquanto isso, vários amigos de juventude do protagonista narrador são presos pela ditadura.

No capítulo 14, a polícia também invade a casa da família, após a prisão de seu irmão. Como efeito colateral da revista policial, o narrador encontra rascunhos de uma carta do pai (reproduzida no livro, figura 2) 
em resposta a uma carta oficial da prefeitura de Berlim, solicitando comprovantes tanto de sua origem ariana quanto de seus ascendentes, necessárias para a adoção do filho por outro casal alemão.

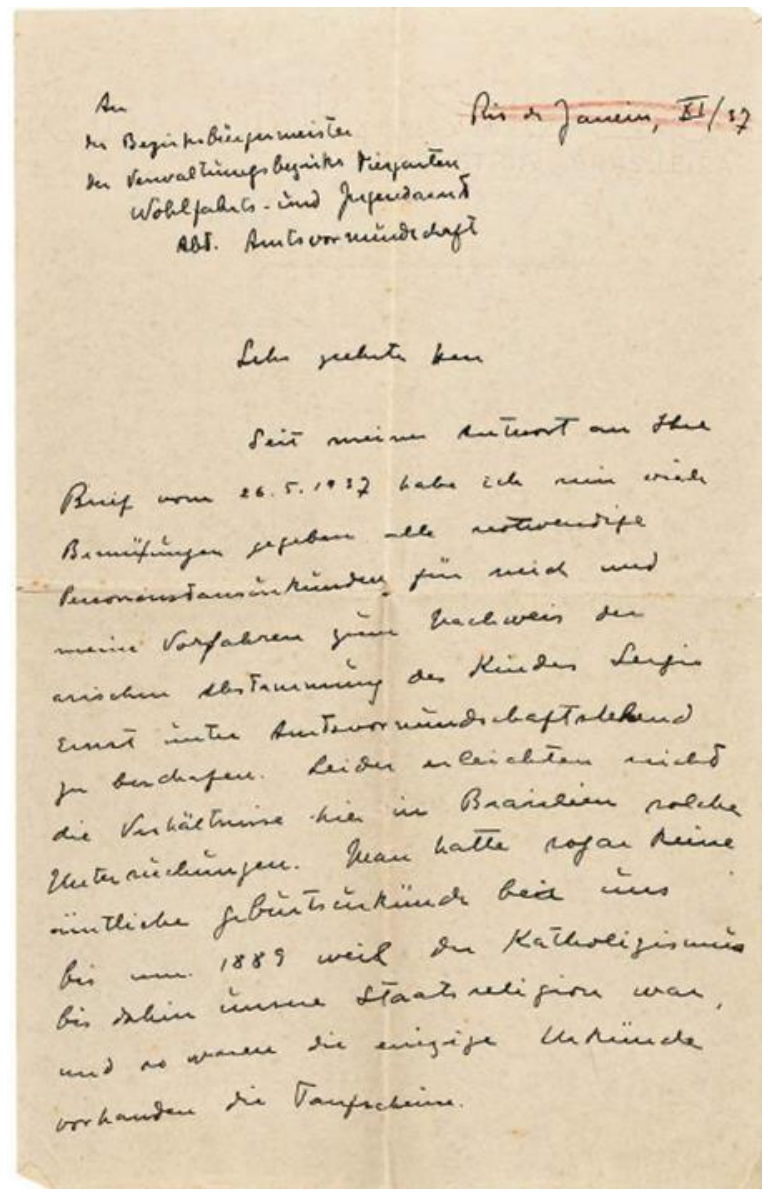

Figura 2 - Manuscrito da carta de Sérgio Buarque de Holanda em resposta às autoridades alemãs (Buarque, 2014, p. 166).

No capítulo 15, morre o pai e, no 16, também a mãe, o que faz surgirem as cartas oficiais, datadas de 24 de setembro de 1934 e 18 de abril de 1935 (ambas reproduzidas no livro), pelas quais foi solicitada a documentação de origem ariana. 
O último capítulo, 17, praticamente um posfácio, abre uma narração extradiegética e conta a viagem do protagonista para Berlim para apresentar, ex posteriori, os fatos conhecidos sobre o irmão alemão.

Concluído o resumo, minha abordagem sobre o livro orienta-se por três enfoques: primeiramente, vou tratar da questão biográfica por meio do conceito de autoficção. O segundo enfoque recai sobre o fenômeno bastante particular das biografias ficcionais hipotéticas do irmão alemão, ou seja, a heteroficção, o que inclui a representação do contexto político, que cumpre uma função pertinente. No terceiro enfoque, desenho outra interpretação do livro, com base no conceito freudiano do "romance familiar".

Como ficou claro pelo resumo, várias informações biográficas sobre o irmão alemão, além de outros dados da história familiar, foram incluídas no texto ficcional. Seria, consequentemente, uma biografia da família? Ou, ainda, uma biografia do próprio autor, isto é, uma autobiografia? Sem querer entrar nos detalhes da teoria sobre a escrita autobiográfica, podemos constatar que, numa definição mais ampla e considerando o debate científico, $O$ irmão alemão não é uma autobiografia. Meu argumento não é que a categoria deveria implicar a representação fiel dos acontecimentos. Sabemos, desde os anos 1970, por exemplo, com Gérard Genette (1969), Philippe Lejeune (1975), Paul de Man (1979), Paul Ricoeur (1990) e outros tantos, que tal representação verdadeira não existe. Em meu entendimento, $O$ irmão alemão não é autobiográfico porque nega o pacto autobiográfico já na orelha, esclarecendo que não deve a verdade ao leitor. Entretanto, podemos operar bem com a categoria autoficção, conceito desenvolvido na teoria literária francesa também nos anos 1970.

À guisa de resumo, novamente sem pretender entrar em detalhes teóricos, podemos constatar com o já notório Serge Doubrovsky (1977), no prólogo de seu romance Fils, que qualquer um pode escrever autoficção, inclusive sem mostrar qualquer distanciamento, sem exame de consciência e, diferente dos tempos das Confessions de Rousseau, sem implorar pela absolvição pelo leitor. Pode, porque a escrita é sempre ficcional, ou seja, a representação do sujeito é, de acordo com Lacan, sempre ficcional. Portanto, autoficção é sempre um jogo, um oscilar difuso entre fato e ficção, entre os pactos referencial e ficcional. Autoficção é uma forma de narração como se fosse (parcialmente) verdadeira. É esse o pacto oferecido ao leitor por Chico Buarque. O que não significa que não conte verdades, dentro dos limites da escrita. Autoficção pode ser 
também uma autobiographie déchaîné (Lecarme e Lecarme-Tabone, 1997, p. 286), na qual o pacto ficcional oculta a verdade factual, muitas vezes para proteger o autor. Desse modo, a autofiç̧ão já foi avaliada como forma de escrita adequada para biografias fragmentadas e transgressoras (Robin, 1991, p. 254), cujo alvo não seria achar a si mesmo, mas inventar a si mesmo.

Portanto, a comparação do texto ficcional $O$ irmão alemão com a narrativa da história familiar dos Buarque de Holanda tem obviamente seus limites, o que ficou patente num dos poucos trabalhos acadêmicos já existentes sobre o livro (Fernandes e Pérez-Laborde, 2014). É claro que existem semelhanças (podemos reencontrar traços do Chico no Ciccio), é claro que também existe fantasia. Mais interessante parece ser investigar o jogo dentro do campo de tensão entre a narração de fatos biográficos e sua ficcionalização.

O livro, por exemplo, inclui imagens das várias cartas mencionadas, uma estratégia narrativa chamada de ilusão de referência. Contudo, entre os documentos utilizados, falta a imagem da primeira carta de Anne para Sergio, a mais importante para a trama, apenas transcrita no texto (o início em alemão, depois numa tradução completa para o português). É provável que ela simplesmente não exista. A tradução ad hoc, feita por um amigo alemão do narrador protagonista, é engenhosa em sua tentativa de reconstruir a sintaxe alemã e o uso de maiúsculas, mas em vários casos "erra a mão", embora isso seja apenas perceptível para um falante da língua alemã. Entretanto, a carta precisava ser inventada, porque ela cumpre a importante função de antecipar o momento da tomada de conhecimento sobre o irmão: o autor Chico descobriu sua existência em 1967, com 23 anos, o protagonista Ciccio em 1960, com 16 anos. Assim torna-se também possível recontar a juventude do protagonista como se ela fosse toda dedicada à busca pelo irmão, além de permitir a inclusão dos deliciosos atos de rebeldia.

Outro caso interessante, em relação à ilusão de referência, é a última foto do livro, mostrando Sérgio Günther abraçado a uma mulher (figura 3). Para quem conhece o local onde a foto foi tirada, algo na perspectiva incomoda. O lugar onde eles posaram é inimaginável (só se for pairando sobre a água...), e a fotografia da ponte ao fundo, entre Berlim Ocidental e Oriental, é razoavelmente conhecida. 


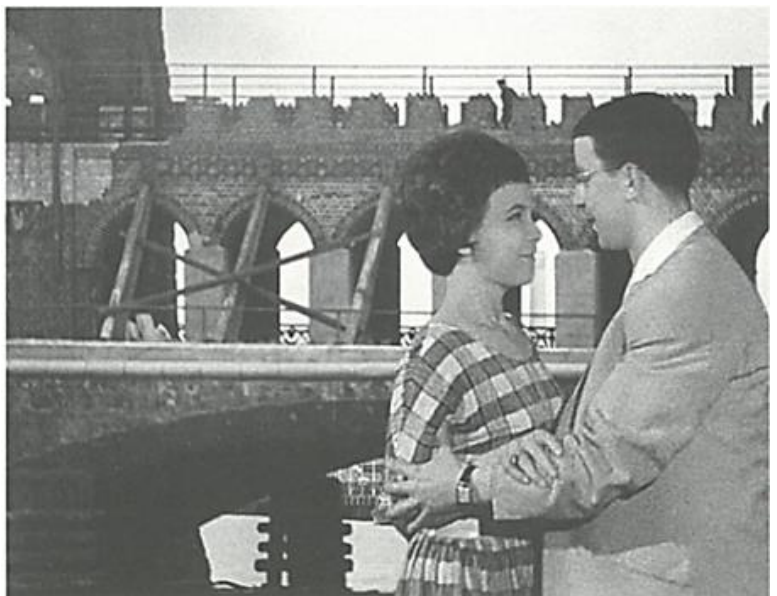

Figura 3 - Fotografia de Sergio Günther com mulher desconhecida (Buarque, 2014, p. 231).

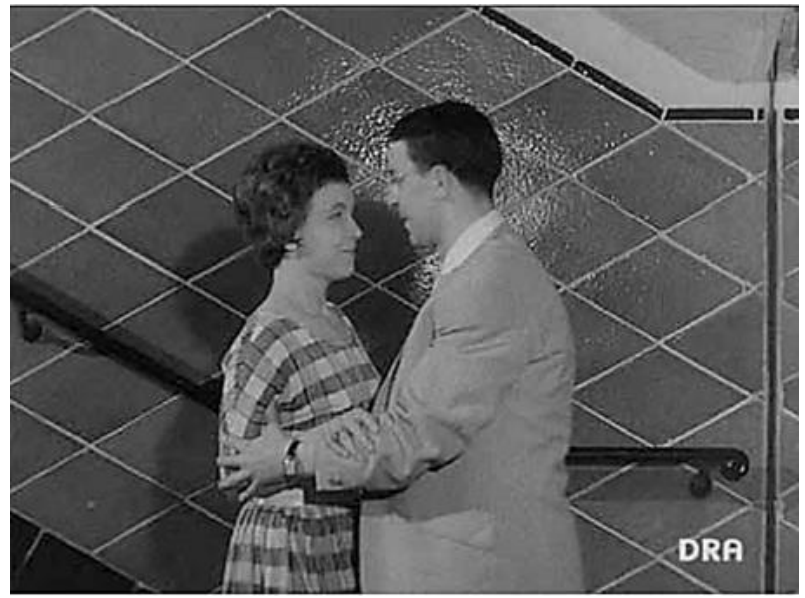

Figura 4 - O original da fotografia do Deutsches Rundfunk Archiv que consta de uma boneca de $O$ irmão alemão. ${ }^{3}$

De fato, trata-se de uma montagem, pois a foto original do Arquivo Alemão de Radiodifusão, que constava numa das bonecas do livro,

${ }^{3}$ Disponível em: <https://goo.gl/tLsnik>. Acesso em: 2 jan. 2016. 
disponível na rede, mostra a mesma cena numa pífia escada de um prédio (figura 4). Isso nos lembra de que nem a reprodução de um documento escapa do processo de ficcionalização - que aqui tem a função de ressoar melhor com a última frase do livro: "Por fim reconheceria não sei de onde os versos que ele cantaria para ela à beira do rio Spree: Dizem/Que em algum lugar/Parece que no Brasil/Existe um homem feliz" (Buarque, 2014, p. 226).

Algo diferente é a situação das biografias ficcionais do irmão alemão. O protagonista narrador, obcecado pelo irmão alemão, cria, para cada informação que foi revelada a ele, uma narrativa que explica a informação e a encaixa na biografia imaginada do irmão. Dessa forma, ao longo do livro, é apresentado um caleidoscópio de "possíveis vidas" do irmão. Na ordem como os fragmentos aparecem no livro, são 12 flashes no total:

1) O irmão alemão teria viajado a São Paulo, com bolsa do Instituto Goethe, mas não chegou a entrar em contato com a família paterna. O que teria acontecido se ele tivesse ligado para casa?

2) O irmão alemão teria virado homme de lettres nas bibliotecas de Berlim, como simulacro do pai, sem sabê-lo.

3) Teriam dito ao irmão alemão que seu pai havia morrido em campo de batalha, mas ele nunca teria acreditado, preferindo à hipótese de que seu pai teria sido assassinado pelos nazistas, embora jamais o tivesse achado nas listas de desaparecidos. Portanto, ele teria se tornado judeu, trocando a biblioteca pela sinagoga.

4) O irmão alemão teria entrado na Juventude Hitlerista e sua mãe teria vindo a trabalhar no Ministério para a Segurança do Estado, a famosa Stasi.

5) A mãe do irmão alemão teria sido a amante de Thomas Mann, roubada por Sérgio na ocasião da lendária entrevista no Hotel Adlon em 1929.

6) Junto com o segundo parceiro da mãe, Heinz Borgart, ele teria emigrado para a França, depois para São Paulo, e depois para Israel. Hipótese sustentada por um livro existente - e uma autobiografia de Varian Fry de 1945: Surrender on demand, consultado pelo 
narrador: "Na página 236, com efeito, vejo que ele sublinhou a lápis um nome no início do segundo parágrafo: Entre os refugiados que cruzaram o Atlântico estavam a cravista Wanda Landowska, o psiquiatra Bruno Strauss, o pianista Heinz Borgart, o escultor..." (Buarque, 2014, p. 61). Trata-se, porém, de um acréscimo imaginado: Fry resgatou mais de 2 mil pessoas, entre eles Hanna Arendt, Heinrich Mann, André Breton, Marc Chagall, Max Ernst e Claude Lévy-Strauss, mas nenhum Heinz Borgart. À moda borgiana, a figura literária é criada a partir de fontes insuspeitas: "Corro os olhos pelas enciclopédias que ocupam duas prateleiras no meu quarto, miro as lombadas da alemã Brockhaus" (Buarque, 2014, p. 62). Prontamente encontra o verbete e cita: "Borgart, Heinz-Frederik (Berlin, 28. November1902), pianista e compositor [...] em 1942 a bordo de um cargueiro em Marselha [...] desembarca no porto de Santos, Brasil, onde [...] residência na cidade de São Paulo" (Buarque, 2014, p. 62-63).

7) Borgart teria abandonado a família em Berlim e Anne teria se casado de novo com um homem modesto,

[...] um ariano que de boa-fé simpatizasse com o nacionalsocialismo, e que ao lado de Anne se vangloriasse do menino perfilado no estádio olímpico de Berlim, a cantar Deutschland über Alles. Já nem duvido que existe veramente uma foto de Sergio de calças curtas e jaqueta cáqui com a suástica na braçadeira, mas desse irmão teria perdido notícias para sempre (Buarque, 2014, p. 69).

8) Mme Beauregard teria roubado o marido Heinz de Anne.

9) Anne teria continuado a se encontrar clandestinamente com Sérgio de Hollander no Museu do Ipiranga (uma hipótese sedutora, pois Sérgio de Holanda de fato foi diretor desse museu entre 1946-56).

10) Anne, na verdade judia e com a sua vida em alto risco, teria confiado Sergio à tutela do Estado para salvá-lo.

11) Sergio teria ido à Alemanha logo depois da guerra, mas o casal Günther, os pais adotivos do menino, tê-lo-iam posto para correr.

12) $\mathrm{Ou}$ teriam trocado o pequeno Sergio por outro órfão, menos suspeito "racialmente". 
Queria observar três aspectos dessas narrativas de heteroficção hipotéticas que ocupam páginas e páginas escritas em futuro do pretérito. Primeiramente, nada foi corroborado pelos fatos, nem os apresentados no livro, nem os fatos extradiegéticos dos quais o autor tomou conhecimento, mas tudo poderia ter sido assim. Bastava uma decisão aleatória diferente, uma circunstância, um mal-entendido. Curiosamente, o que, na narração do livro, dá origem à gênese do irmão alemão, é um mal-entendido: Anne Ernst teria tomado o Herr (Sérgio de) Hollander pelo compositor (Friedrich) Holländer e Sérgio a Fräulein (Anne) Ernst pela famosa bailarina (Lily) Ernst. Segundo, a mesma estratégia narrativa invade, no final, a escrita autoficcional, quando o narrador protagonista imagina-se preso, torturado e assassinato pela ditadura no capítulo 16 (Buarque, 2014, p. 187), o que torna ainda mais explícito o suposto projeto de explorar biografias possíveis, incluindo a própria. Terceiro, a presença de comprometimentos políticos culpáveis ou condições de vitimização por terrorismo de Estado.

Esse último ponto vale ser explorado mais: afinal, a narrativa trata de vários períodos que interferiram, mais ou menos rigidamente, nas vidas dos seus cidadãos: o nazismo na Alemanha, o socialismo na Alemanha Oriental e a ditadura militar no Brasil - incluindo possíveis nexos. Não é a toa que o amigo Udo, que traduziu a primeira carta para o Ciccio, tem o sobrenome Heydrich: Reinhardt Heydrich foi o principal responsável pela organização do Holocausto e morreu alvo de um atentado em 1942. Também já mencionei a figura literária do Heinz Borgart, refugiado judeu. A questão "quem é" ou "quem poderia ter sido judeu" aparece repetidas vezes no livro. Holländer (com trema no a) era um sobrenome frequente entre judeus alemães. Provavelmente, o nome deve-se, originalmente, ao pogrom de Lisboa, em 1506, e o êxodo da comunidade judaica para Amsterdã e, de lá, subindo o rio Reno, para toda a Europa Central. Para dar apenas um exemplo, além do já mencionado Friedrich Holländer, a mãe de Anne Frank também se chamava Edith Frank-Holländer; e mais de 1 mil pessoas portadoras desse sobrenome foram assassinadas na shoah, como informa uma consulta à base central de dados de nomes de vítimas da shoah do The World Holocaust Remembrance Center Yad Vashem. ${ }^{4} \mathrm{O}$ nome "Holanda" já não mais provoca essa associação no Brasil, como é

\footnotetext{
${ }^{4}$ Disponível em: <http://yvng.yadvashem.org〉.
} 
alegado pela narrativa, além de fazer os protagonistas "judeus" devorarem carne de porco em quantidades industriais; incluindo o próprio Sérgio de Hollander, para quem o narrador inventou um avô judeu de nome Arnau de Hollander - inspirado na figura histórica Arnau de Hollanda, figura influente em Pernambuco do século 16, tido como ancestral da família pelas várias biografias familiares.

A ambiguidade do "ser judeu", entre confissão, ascendência ou nome de família e mera suspeita ou projeção do Estado terrorista, é explorada de forma bem sutil no livro. Mesmo que a carta que solicitava comprovantes de origem ariana a Sérgio Buarque de Holanda deixe a entender que, pelo lado da mãe, já existia a referida documentação - ou seja, que ela não teria sido considerada judia -, o autor a faz morar na Rua Fasanenstrasse 22, ex-propriedade (até a expropriação em 1937) da família judia Wertheim e com vários moradores entre as vítimas do nazismo, como informa uma placa comemorativa, em formato de "pedras-obstáculo", no passeio em frente ao prédio no qual hoje em dia funciona o charmoso Hotel Augusta (figura 5). É provável que Chico Buarque, durante suas investigações, tenha reparado nela.

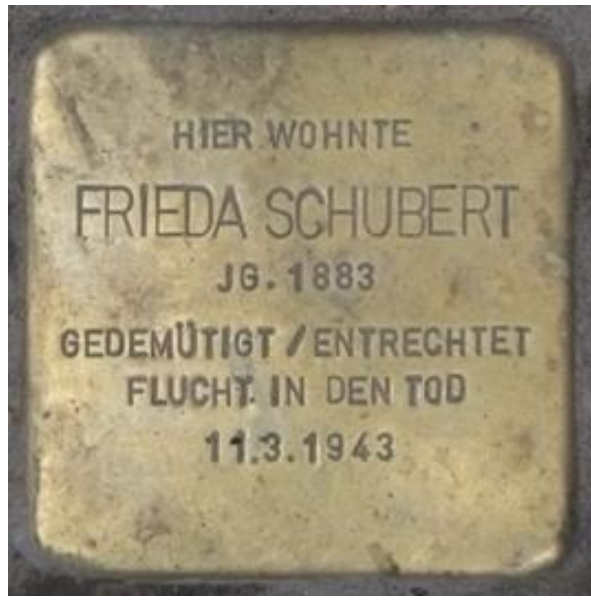

Figura 5 - Fotografias de "pedra-tropeço" em frente ao endereço da Rua Fasanenstrasse 22.5

${ }^{5}$ Disponíveis em: <https://goo.gl/XXnWfs>. Acesso em: 29 mar. 2016. 
A ditadura militar brasileira também se faz presente como pano de fundo dos capítulos 5 a 16 e, nos casos mencionados, interferindo como agente no desenvolvimento dos acontecimentos. A ditadura do proletariado na RDA, entretanto, é quase ausente, pelo menos à primeira vista. Contudo, consta no livro um trecho muito significativo: quando o irmão maior do narrador - de nome Domingos, não Sergito nem Álvaro -, que possui uma voz irresistível, passa a trabalhar como locutor de rádio, não apenas para comerciais mas também gravando propaganda oficial para o regime - do tipo "quem não vive para servir ao Brasil, não serve para viver no Brasil" (Buarque, 2014, p. 72) -, podemos reencontrar nesse irmão o próprio Sergio Günther.

No terceiro enfoque, pretendo abordar a questão dos laços de família. Pelo dito, poder-se-ia chegar à conclusão de que $O$ irmão alemão teria caraterísticas de um romance de geração, subgênero cada vez mais importante desde os anos 1990, que reconstrói uma história familiar, tipicamente contemplando períodos históricos conturbados. De fato, o segundo capítulo pode ser lido, sim, como uma homenagem ao pai do autor, Sérgio Buarque de Holanda. Porém, e como já observado por Fernandes e Pérez-Laborde (2014), a representação da mãe é puramente imaginária, desenhada como pessoa humilde, além de italiana estereotipada, e praticamente uma servidora do pai: “Ao pé da estante vejo a minha mãe de cócoras, buscando algum título a mando do meu pai" (Buarque, 2014, p. 10). A existência do irmão alemão aparenta ser do conhecimento da mãe, embora ela nunca comente diretamente.

Sei que meu pai ainda solteiro morou em Berlim entre 1929 e 1930, e não custa imaginar um caso dele com algum Fräulein por lá. Na verdade, acho que já ouvi falar de algo mais sério, acho até que há tempos ouvi em casa mencionarem um filho seu na Alemanha. Não foi discussão de pai e mãe, que uma criança não esquece, foi como um sussurro atrás da parede, uma rápida troca de palavras que eu mal poderia ter escutado, ou posso ter escutado mal (Buarque, 2014, p. 9-10).

Consequentemente, o narrador se pergunta como ela teria lidado com a presença dos vestígios da Anne por toda parte e dá a resposta: com estoicismo. Os filhos do casal se resumem a dois, tirando o irmão alemão: Ciccio (narrador protagonista) e o primogênito brasileiro (Domingos, apelidado Mimmo). Este recebe todo destaque na narrativa como "superior" a ele em todos os sentidos: é mais bonito e menos tímido, 
conquistador de todas as moças virgens; faz carreira emprestando seu vozeirão para comerciais e de rádio; é mimado pela mãe que, já no leito da morte, acompanhada pelo narrador protagonista, só quer saber do seu Mimmo; e, o mais importante, tem uma ótima e íntima relação como o pai. Num momento-chave da trama, Ciccio, durante um jantar e depois de muita hesitação, ousa perguntar sobre o irmão "alemão", mas é completamente ignorado pelo pai, que prefere comentar uma foto da Playboy, escondida pela mesa, que o irmão maior está lendo no colo: "que lombo!" (Buarque, 2014, p. 52). Além do mais, para esse filho que nunca mostrou o mínimo interesse pelo irmão alemão, o pai confiou algumas das cartas que só na hora da revista policial aparecem diante dos olhos do caçula, que, ansiosamente, procurava por quaisquer vestígios. O elemento da trama lembra o clássico drama psicológico do "segundo filho", que se sente negligenciado e procura entender o que lhe falta em comparação com o primogênito - mas talvez seja mais que isso.

$\mathrm{O}$ "outro irmão" brasileiro, na verdade, mistura-se com o alemão ou, progressivamente, é substituído por ele. Enquanto o irmão brasileiro desaparece, sequestrado pela ditadura, o irmão alemão se torna mais concreto, através da investigação. Isso é apenas insinuado, no seguinte trecho, no último parágrafo da história contada, no qual o narrador confabula:

E meus olhos talvez se embaçassem ao vislumbrarem a imagem em preto e branco, na outra margem do rio, do meu irmão Sergio. É o Mimmo, eu pensaria alto [...]. Passaria mesmo pela minha cabeça que Sergio Günther fosse o próprio Mimmo, aos trinta anos de idade, exilado em Berlim Oriental com passado nebuloso e nome falso (Buarque, 2014, p. 225).

Podemos interpretar disso que o desvendamento do imaginado, por tornar-se real, pode representar também uma desilusão. O reino da fantasia, a especulação sobre um familiar desconhecido, é um espaço criativo privilegiado. No final do livro, o narrador protagonista, já em Berlim e perto de descobrir o segredo, é confrontado com um caso similar: um dos informantes alemães dele, Wolfgang Probst, conta que nunca conheceu o pai, pois este teria morrido na Segunda Guerra Mundial. Mesmo assim, ele decidiu para si que, na verdade, o pai teria sobrevivido à guerra e tomado domicílio em Paris. Volta e meia, ele viajaria para Paris para se deleitar com a ideia de como seria reencontrá-lo - algo que nunca deveria acontecer, obviamente, porque acabaria com o jogo prazeroso. 
Mais que um romance de geração, o livro parece voltar a tematizar a eterna busca pelos pais ausentes. Na verdade, há um indício já no peritexto: o livro que leva o irmão alemão no título também leva a dedicatória "para Sergios" - o que faz entender que pode se tratar de, pelo menos, dois: Sergio Günther e Sérgio de Holanda. No capítulo 13, o narrador, que até agora não conseguiu realizar nada dos seus planos, de repente se empolga, achando que seria "capaz de escrever um romance inspirado na Alemanha dos anos 30, tão presente nas minhas leituras e fantasias [...], por exemplo a história de Anne Ernst" (Buarque, 2014, p. 148). Logo depois, ele se dá conta que a empolgação deriva do sentimento de que o livro poderia ser uma ferramenta para quebrar o muro invisível que o separa do pai. Imagina que poderia chegar com o livro pronto, de forma que, pela primeira vez, ele seria enxergado, reconhecido, aceito pelo pai. Seria o livro que ele escreveria não apenas para "esse misterioso papai" finalmente desvendar para ele o segredo (ou a sua versão) do irmão alemão. "O que não seria de todo inviável, caso ele viesse a saber que me tornei um homem de letras" (Buarque, 2014, p. 150). Seria, principalmente, o livro para se confraternizar com o pai, frente ao irmão e à mãe: "E que a partir daí só nos comuniquemos em alemão, para desgosto do meu irmão e suspicácia da minha mãe, que sem entender palavra verá o marido deixar de lado o prato para comentar o quão fascinante lhe pareceu a jovem A.E." (Buarque, 2014, p. 151). Uma fraternização da relação com o pai no reino da fiç̧ão. Talvez também o perdão pelo seu pecado original: Ciccio, enquanto criança, tinha "inutilizado" a primeira edição de Hans Staden, uma das pérolas nas estantes do pai, "espicaçando página por página e mijando em cima" (Buarque, 2014, p. 18). Nesse sentido, O irmão alemão poderia ser lido por meio do conceito do "romance familiar", cunhado por Freud (1909/1972), no qual um sujeito intenta, pelas fantasias (aqui narrativas), trabalhar ou modificar o vínculo com os pais e irmãos. No documentário Chico: artista brasileiro, dirigido por Miguel Faria Jr., que estreou em novembro de 2015, Chico Buarque menciona que foi pela literatura que rompeu o muro que o distanciava do pai. Temos então, nessa ficcionalização, pelo menos uma pista para uma referencialidade autobiográfica.

Para finalizar, queria observar o impulso de internacionalização experimentado pelo livro. O irmão alemão, que no Brasil já vendeu mais de 100.000 cópias (provavelmente o título de ficção brasileira mais vendido nos últimos dois anos), já foi traduzido para o francês e para o alemão e em breve será lançado em inglês. Mas, independentemente disso, é uma 
obra de cunho "internacional". Por quê? Porque, em primeiro plano, aborda uma grande questão universal: o que meus antecedentes familiares fizeram durante épocas de grandes crises? Ou o que poderiam ter feito? Essa vertente da literatura de testemunho ou memorialista é bem estabelecida e até aí nenhuma novidade. O que me parece ser novidade é que Chico Buarque, aproveitando o gancho do incidente familiar, lança um olhar sobre a Alemanha nazista e o holocausto. O olhar é diferente, porque imagina in loco, não a partir de uma comunidade de emigrantes, diferente do que fez, por exemplo, Michel Laub em Diário da queda (2011), ou Luís Krausz em Desterro: memórias em ruínas (2011). ${ }^{6}$ O resultado é um olhar refrescante e descomprometido sobre um capítulo traumático da história nacional alemã - já não mais com os direitos de ficcionalização reservados - como literatura do mundo, ou pelo menos com instinto de internacionalidade. Existe um longo debate sobre a razão de escritores do "centro" poderem tematizar e ficcionalizar o mundo inteiro em seus textos, enquanto os escritores da "periferia" restringiamse a ficcionalizar o próprio contexto. Definitivamente, isso mudou nos últimos anos, e $O$ irmão alemão é um bom exemplo disso.

\section{Referências}

BUARQUE, Chico (2014). O irmão alemão. São Paulo: Companhia das Letras.

DE MAN, Paul (1979). The rhetoric of romanticism. New York: Columbia University Press.

DOUBROVSKY, Serge (1977). Fils. Paris: Galilée.

FERNANDES, Márcia; PÉREZ-LABORDE, Elga (2014). Duas faces de uma mesma moeda: na fronteira da autoficção pós-moderna em $O$ irmão alemão, de Chico Buarque. Cerrados, Brasília, v. 23, n. 38, p. 161-173.

FREUD, Sigmund (1909/1972). Der Familienroman der Neurotiker. In: FREUD, Sigmund. Gesammelte Werke: Werke aus den Jahren 1906-1909. Frankfurt am Main: S. Fischer, v. 7, p. 225-231.

\footnotetext{
${ }^{6}$ Algo parecido, guardadas as devidas proporções, tem acontecido com a apropriação do nazismo e do holocausto como tema por escritores alemães com ascendência turca - leia-se, não comprometidos: Hilal Sezgin, com a A morte do costureiro (1999), Zafer Senocak, em Foi Hitler árabe? (1994), e as performances de Serdar Somuncu sobre a Minha luta (desde 2000), para citar apenas alguns (traduções dos títulos minhas).
} 
GENETTE, Gérard (1969). Figures III. Paris: Seuil.

HOLANDA, Bartolomeu Buarque de (2007). Buarque - Uma família brasileira. Rio de Janeiro: Casa da Palavra.

LECARME, Jacques; LECARME-TABONE, Eliane (1997). L'autobiographie. Paris: Armand Colin.

LEJEUNE, Philippe (1975). Le pact autobiographique. Paris: Seuil.

MOTA, Urariano (2005). O rei Roberto Carlos e a ditadura militar no Brasil. Carta Maior, São Paulo, 5 maio 2005. On-line. Disponível em: https://goo.gl/6KRdt0. Acesso em: 29 mar. 2016.

NEHER, Clarissa (2014). Historiador revela detalhes sobre "irmão alemão" de Chico Buarque. Deutsche Welle Brasil, 21 nov. On-line. Disponível em: http://dw.com/p/1DrJR. Acesso em: 29 mar. 2016.

RICOEUR, Paul (1990). Soi-même comme un autre. Paris: Seuil.

ROBIN, Régine (1992). L'autofiction. Le sujet toujours en défaut. In: FRÉDÉRIC, Madelaine (Org.). Entre l'histoire et le roman. La littérature personelle. Bruxeles: Centre d'études canadiennes de l'Université libre de Bruxelles, p. 231-265.

SILVA, Fernando de Barros e (2015). O irmão brasileiro: a busca de Chico Buarque em Berlim. Público, Lisboa, 25 jan. On-line. Disponível em: https://goo.gl/qsfzdH. Acesso em: 29 mar. 2016.

TRZOSS, Siggi (2009). Lexikon - Schlager des Ostens. Berlin: Aperçu.

ZAPPA, Regina (2007). Para seguir minha jornada: Chico Buarque. Rio de Janeiro: Nova Fronteira.

Recebido em fevereiro de 2016.

Aprovado em julho de 2016.

\section{resumo/abstract/resumen}

\section{A propósito de um irmão alemão: a ficcionalização de um assunto internacional de família}

Georg Wink

Num contexto de reivindicações na literatura brasileira, veiculadas por novas vozes sociais, qual é a relevância de um grande nome da cultura brasileira, Chico Buarque ( $\left.{ }^{*} 1944\right)$, aos 70 anos, tomar conhecimento da existência de um meio-irmão alemão, 
Sergio Günther Ernst (1930-1981)? Irmão com quem nunca teve contato algum, já falecido há 30 anos? A princípio, nenhuma. Entretanto, o incidente internacional na história familiar do autor serviu como inspiração e fábula para o romance $O$ irmão alemão, publicado em 2014, que se revela uma obra complexa pela sua transgressão de divisões de caráter diegético, político e cronológico. Neste artigo, pretendo examinar como a narrativa combina fatos e, inclusive, documentos históricos com uma trama imaginativa; como explora, indiretamente, a história traumática de regimes autoritários; e como trabalha, por meio de um "romance familiar", as fantasias pelas quais estabelece vínculos com o pai e os irmãos.

Palavras-chave: autoficção, heteroficção, romance familiar, Chico Buarque.

\section{À propos a German brother: the fictionalization of an international family affair}

Georg Wink

In framework in which new social voices in Brazilian literature make claims, what could be the relevance of Chico Buarque (1944), a well-known name in Brazilian culture, learning, at the age of 70, about the existence of his German half-brother Sergio Günther Ernst (1930-1981)? A brother that Buarque never met and who already had passed away 30 years ago? At first glance, there is none. Nonetheless, the international incident in the author's family history served as inspiration and background story for the novel $O$ irmão alemão, published in 2014. This text reveals itself as quite complex due to the transgression of its diegetic, political and chronological borders. In this article I examine how Buarque's narrative combines facts and historical documents with an imaginary plot; how the book indirectly explores the traumatic history of authoritarian regimes; and how the narrator uses this "family novel" to work through the fantasies through which he establishes a relationship with his father and brothers.

Keywords: autofiction, heterofiction, family novel, Chico Buarque.

\section{A propósito de un hermano alemán: la ficcionalización de un asunto internacional de familia}

Georg Wink

En el contexto de reivindicaciones en la literatura brasileña, expresadas por la aparición de nuevas voces sociales, ¿cuál es la relevancia de que un gran nombre de la cultura brasileña como el de Chico Buarque ( $\left.{ }^{*} 1944\right)$, a los 70 años tenga conocimiento de la existencia de un medio hermano de padre alemán llamado Sergio Günther Ernst (1930-1981)? ¿Un hermano con quien jamás tuvo contacto alguno y fallecido ya hace 30 años? En principio, ninguna. No obstante, éste 
incidente internacional en la historia familiar del autor ha servido como inspiración y fábula para la novela $O$ irmão alemão, publicada en 2014, la cual se revela como una obra compleja por su transgresión de las divisiones de carácter diegético, político y cronológico. En este artículo pretendo examinar cómo la narrativa entrelaza hechos $\mathrm{y}$, de hecho, documentos históricos con una trama imaginativa; cómo explora, indirectamente, la historia traumática de los regímenes autoritarios; y cómo trabaja, a partir de una "novela familiar", las fantasías por las cuales establece vínculos con el padre y los hermanos.

Palabras clave: autoficción, heteroficción, novela familiar, Chico Buarque. 